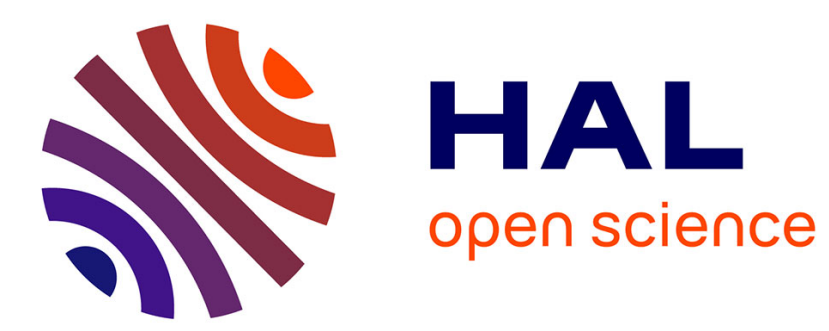

\title{
LIQUID METAL ION SOURCES AS THRUSTERS FOR ELECTRIC SPACE PROPULSION
}

\author{
J. Mitterauer
}

\section{To cite this version:}

J. Mitterauer. LIQUID METAL ION SOURCES AS THRUSTERS FOR ELECTRIC SPACE PROPULSION. Journal de Physique Colloques, 1987, 48 (C6), pp.C6-171-C6-176. 10.1051/jphyscol:1987628 . jpa-00226831

\section{HAL Id: jpa-00226831 https://hal.science/jpa-00226831}

Submitted on 1 Jan 1987

HAL is a multi-disciplinary open access archive for the deposit and dissemination of scientific research documents, whether they are published or not. The documents may come from teaching and research institutions in France or abroad, or from public or private research centers.
L'archive ouverte pluridisciplinaire HAL, est destinée au dépôt et à la diffusion de documents scientifiques de niveau recherche, publiés ou non, émanant des établissements d'enseignement et de recherche français ou étrangers, des laboratoires publics ou privés. 


\section{LIQUID METAL ION SOURCES AS THRUSTERS FOR ELECTRIC SPACE PROPULSION}

\section{J. Mitterauer}

Institut für Allgemeine Elektrotechnik und Elektronik Technische Universität Wien, Gusshausstrasse 27-29, A-1040 Wien, Austria

Abstract: Electric space propulsion systems are characterized accord3.19 their interent features and specified domains of application in space missions. Particularly the Field Emission Electric Propulsion (FEEF)-system using a 1 iquid metal ion source as a thruster is described and recent results on its emission performance are presented.

\section{INTRODUCTION}

Space propulsion by mass expulsion actually can be performed by conversion of chemically stored thermal energy on the one side or electric energy on the other side into kinetic energy of the expelled mass. In the case of chemical propulsion, the amount of energy released is limited by the energy content of the chemical propellants. Chemical propulsion is therefare energy 1 imited but not power 1 imited; compared with electric propulsion, chemical propulsion is characterized by relative high thrust and low exhaust velocity.

In the case of electric propulsion, electric energy normaliy being converted from solar radiation energy is used to supply or augment the kinetic energy necessary for mass expulsion. Bearing in mind the practical limitations of electric power and propellant mass on board of the spacecraft, electric propulsion is therefore power 1 imited but not energy limited. Compared with chemical propulsion, electric propulsion is characterized by relative low thrust and high exhaust velacity.

The application of electric propulsion to space missions is restricted by $i$ ts inherent characteristics, i.e. above all high exhaust velocity, high specific electric power and high operating voltage: From these primary characteristics there result derived characteristics for space applications: Low propellant mass (typically about 10\% of that required with advanced chemical propellants), low thrust level, long operating duration due to the low thrust (typically $5.10^{3} \mathrm{~h}$ ), electrical power conversion and finally the necessity of ion beam neutralization in the case of electrostatic systems in order to avaid electrostatic charging of the spacecraft.

On the other hand, the inherent characteristics of electric propulsion offer specified domains of their application in space missions:

- Orbit control or stationkeeping of geostationary satellites

- Disposal of spent or failed satellites from geostationary orbit

- Atmospheric drag compensation of low orbit spacecraft

- Interplanetary space missions with high energy demand

- Control of spacecraft charging 
The slit emitter module

The slit emitter module in principle consists of two symmetrical highly polished metal plates of the shape depicted in Fig-1. In one or both of the emitter halves there is milled a recess to be of use as a reservoir of the 1 iquid metal supplied to the emitter module by a feeding capillary tube. On certain regions of one of the inside faces there is sputter deposited a layer of nickel with a thickness of the order of $10^{-\infty} \mathrm{m}$. When the two halves are tightly clamped together they are separated by the thickness of this layer, thus forming a narrow slit through which the 1 iquid metal can flow and be transported ta the edges of the 51 it by the action of capillary forces. The material used for the emitter fabrication is stainless steel and, more recently, Inconel $\times 750$ which has shown better wetting characteristics for caesiun, the liquid metal used for most of the emitter tests because of its superior wetting characteristics, low melting point and high atomic mass.

Thruster, propellant system and power conditioning unit

The FEEF thruster basically comprises the emitter which is kept at a positive voltage, the accelerator, kept at negative voltage and which is used as a counter-electrode to establish the field needed for ionization and finally the neutralizer in order to avoid electrostatic charging of the spacecraft. As illustrated in Fig.2, the complete FEEF system comprises:

- One or more thrusters and neutralizers

- A propellant system

- A power canditianing unit

The proposed neutralizer for the future development is a plasma bridge neutralizer fed also by caesium which can be operated with very low mass flow rates of approximately only $4 \%$ of the main flow rate or less. The propel lant tank is a metallic bellows device pressurized far caesium expulsion by heated zeolite. The power conditioning unit consits of a thruster dedicated power supply module utilizing advanced technology in power conversion.

The main advantages of a propulsion system based on the field emission principle are:

- Mechanical, electrical and operational simplicity

- Emitter clustering capability

- Continous thrust throttling from zero to maximum

- Active control of the spacecraft potential by the neutralizer

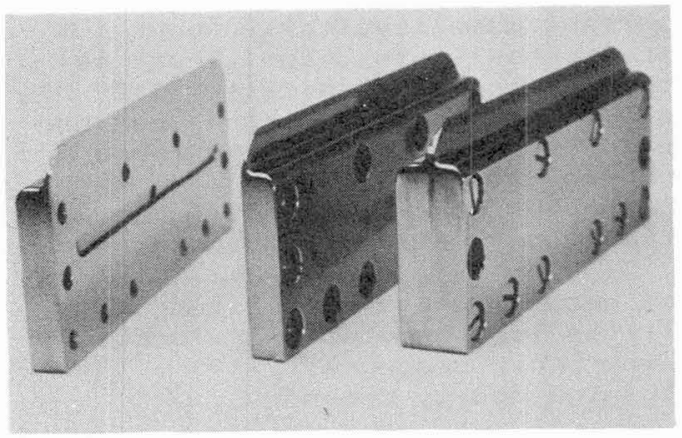

Fig.1: 51 it emitter module in original size

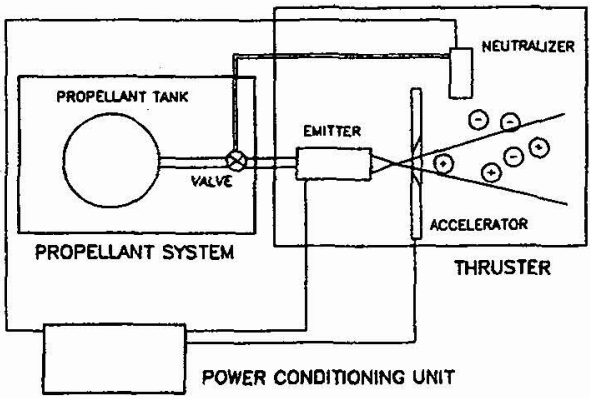

Fig. 2: Basic design of the FEEP-system 


\section{THE FIELD EMISSION ELECTRIC PROPULSION SYSTEM}

In 1972, the European Space Agency (ESA) started the development of an advanced concept of electric propulsion based on the field emission principle; the application of this principle in liquid metal ion sources (LMIS) has resulted in a high specific impulse ion thruster called FEEP (Field Emission Electric Propulsion). This activity has been carried out at the European Space Fesearch and Technology Centre (ESTEC) in Noordwijk under the ESA Technological and Research Programme/1/. Major activities in research and development sponsored by ESA furthermore are being pursued at the Societe Europénne de Propulsions (F), at the Fulmer Research Institute (UK), at the University of Pisa (I) and finally at the Technical University of Vienna (A).

The field emission principle

In a field emission electric propulsion system the ions being expelled are created directly from the surface of a liquid metal exposed to vacuum by means of a high electric field resulting from suitable voltages applied to an enitting electrode geometry. When the surface of a liquid metal is subjected to a high electric field it is distorted into a cone or a series of cones which protrude more and mare from the surface with increasing field strength. The onset of ion emission accurs when the applied total voltage between the emitter and accelerator electrode is in excess of a critical value which is called the onset voltage. When the field reaches values of the order of $10^{\circ} \mathrm{m}^{-1}$, atoms of the metal tip are ionized either by field evaporation or field ionization; the free electrons are rejected into the bulk of the liquid metal while the ions are accelerated and expelled from the emitter by the same electric field which has ionized them, creating therefore the thrust. Because the radius of curvature at the apex of such a cone is of the order of $10^{->m}$ or 1 ess, applied val tages of the order of 10 s fields.

Considering one of the most advanced physical models of the ion emission pracess /2/, field evaporation is claimed to be the dominant mechanism of ion formation, but it also was found that thermal evaporation followed by field ionization may make a significant contribution to the total ion current. Field ionization, unlike field evaporation, can occur also in a region of the order of 10-9m wide above the apex of an emitting cone, where thermally evaporated neutral atoms and clusters (also emanating from the shanks of the cone) were attracted by polarization forces. Contrary to field evaporation, the field ionization mechanism gives rise to singly charged ions oniy. Bearing in mind finally the obviously inherent feature of this mechanism to emit beneath atomic ions and molecular ions of minor percentage 13/ even charged clusters and microdroplets (the diameter of the latter ranging between $10^{-7 m}$ to $10^{->}(\mathrm{m})$, a new scope for speculation on vapor production processes is offered. Experimental evidence on neutral emission support the view that virtually all of the neutral mass is emitted as microparticles $/ 3 /, / 4 /, / 5 /$. These are interpreted as aggregates of neutral atoms carrying a surface charge such that the inward surface tension forces approximately are balanced by the outward electric forces. It is known that for microparticles with diameters less than about $2.10^{-7 m}$ the effective surface tension decreases as a result of the gross curvature of the liquid surface /5/. One would expect therefore that microparticles in this range would be unstable and would dissociate under the outwards electric forces, contributing probably to the supply of neutral atoms and clusters mentioned above. 


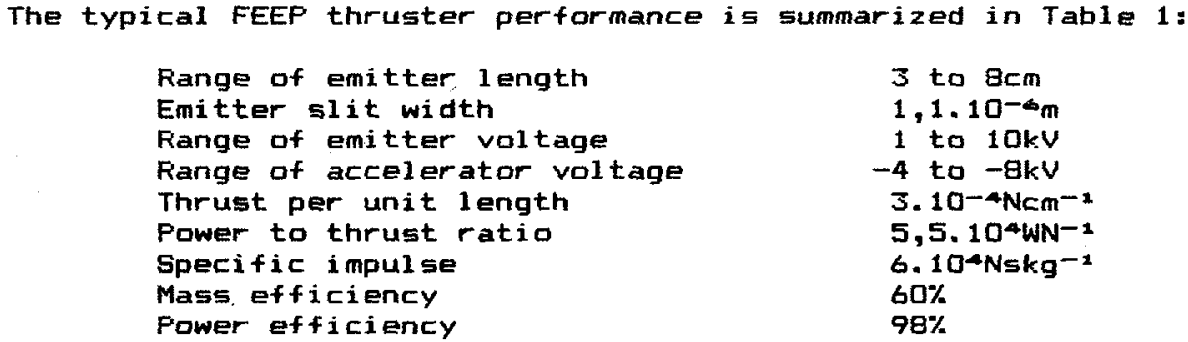

\section{EMISSION PERFORMANCE OF THE FEEP SYSTEM}

Fecent investigations have demonstrated the outstanding importance of both the residual gas atmosphere and the emitter preparation technique on the emission performance of FEEP thrusters /4/,/6/. In addition, very recentiy, the capability of FEEF thruster operation in the pulsed mode has been demonstrated, thus opening the possibility of utilising this system for new domains in application like extreme fine positioning of spacecraft $/ 7 /$.

\section{Emission site distribution and specific thrust}

If the slit emitter is filled with 1 iquid metal and the surfaces of the $=1$ it are uniformly wetted, a homogeneous linear liquid tip of semicylindrical shape is assumed to exist at onset conditions. Enhancing the electric field, this tip is distorted; equidistant spaced enitting sites are originating along the extension of the emitter slit, each of them contributing to the ion beam.

In order to maintain these conditions, the emitter is heated and outgassed at an ultimate background pressure of about 5.10-20mbar and then is supplied with caesium of extreme purity. Complete and perfect wetting is obtained, resulting in an instantaneous firing of the emitter and being characterized by a nearly homogeneous distribution of equidistant emission sites, the linear density of the latter being about $1200 \mathrm{~cm}^{-1}$. The measured spacing of about $7,5.10^{-6 m}$ is in good agreement with calculations according to a standing wave theory of surface instabilities $/ 6 /$.

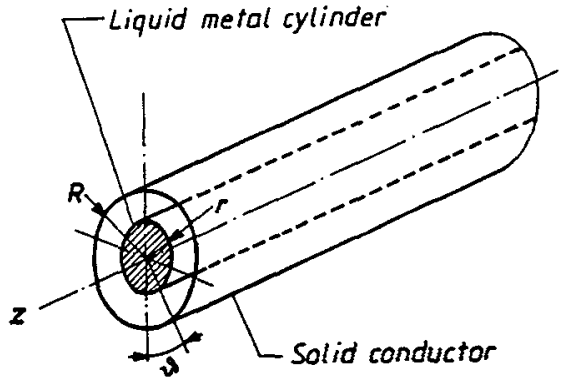

(a)

Fig.3: Equilibrium configuration of a liquid metal conductor in an electric field of cylindrical symmetry

(a) Electrode configuration

(b) Axially symmetrical varicose mode of the liquid metal 
The mathematical treatment of this problem has been discussed in some detail $/ 8 /, / 9 /$, considering especially standing wave perturbations with no time variations. Among these, the analysis of a cylindrical case seems to be of special relevance to the slit emitter, where it is assumed that the initial shape of the linear liquid metal tip just before emission onset is of semicylindrical geometry. One considers an infinitely long circular cylinder of radius $r$ made of 1 iquid metal to be placed in a hollow metal cylinder of radius $R$ as it is outlined in Fig- $3(a)$. The initial pre-perturbation equilibrium condition is given

$$
E_{0} E_{0} 2 / 2=\sigma / r
$$

where $E_{0}$ is the initially uniform electric field at the surface of the liquid cylinder and $\sigma$ the surface tension of the liquid metal. A small perturbation $r$ of the radius is applied which is assumed to be sinuscidal in both 9 and 2 ; Laplace's equation then is solved for the resulting perturbed potential $\phi$

$$
\Phi^{\prime}=H\left(r^{\prime}\right) \exp (j m g) \exp (j k z)
$$

where $H\left(r^{\prime}\right)$ is a Hankel function. For the mode $m=0$ which is the normal axially symmetrical varicose mode shown in Fig. 3 (b) there exist two solutions

$$
k_{2} r=2 \text { and } k_{2} r=0,2
$$

Considering the relation

$$
k=2 \pi / \lambda
$$

the resulting wavelengths of the varicose mode are

$$
\lambda_{2}=\pi \text { and } \lambda_{2}=10 \pi
$$

In order to decide which of the two perturbation wavelengths may apply, a comparison was made between the results of a standing wave approach for the plane case $/ 10 /$ and the present values; as the smaller wavelength $\lambda_{1}$ corresponds quite well with the former results, this value was selected for the further considerations.

The capability of such a thruster to operate at rather high values of the specific emission current of $5.10^{-5} \mathrm{Acm}^{-1}$ and more without any current saturation was demonstrated succesfully $/ 6 /$. The calculated specific thrust of about $7.10^{-4 \mathrm{Ncm}^{-1}}$ resulting for this specific current is considerably above the values measured for a comparable thruster at ESTEC.

\section{Fulsed operation mode}

The need for ultra-fine attitude contral of spacecraft for future scientific missions and the unique combination of low thrust and extremely fast switching capability offered by a FEEP thruster had stimulated the interest on the FEEF system performance when operated in the pulsed mode; therefore several dedicated experiments have been carried out to assess the emission characteristics of a FEEP thruster operating with a pulsed power supply unit/7/:

The pulse characteristics of voltage and current follow quite closely the corresponding values of FEEP thrusters operated in the continous mode. Several pulse frequencies ranging from 50 to $5.10^{-a} \mathrm{~Hz}$ have been explored; the minimum pulse length which can be achieved is in the range of $10 \mathrm{~ms}$ with emission currents of about $3.10-0 A$; this is equivalent to a thrust 1 evel of $3.10^{-o N}$ and an impulse bit of $3.10^{-0 N}$ which is far beyond the capabilities of any chemical propulsion system. 


\section{REFERENCES}

/1/ C. Bartoli and W. Berry: "Review of European electric propulsion developments", 19th Int.Electric Propulsion Conference, Col orado Springs, Paper AIAA-87-1099 (1987)

(2/ D.R.Kingham and L.W.Swanson: "Mechanism of ion formation in 1 iquid metal ion sources", J.Physique 45, C9/133-138 (1984)

/3/ J.Mitterauer: "Spectroscopic investigations of a field emission generated radiative zone; Mass spectroscopic measurements", Final Report on ESTEC-Contract $2734 / 76$ (1981)

ESA Report Reference CR (P) 1589

14/ J.Mitterauer: "Field emission electric propulsion: Spectroscopic investigations on slit emitters", Final Report on ESTEC-Contract $5051 / 82$ (1985), ESA Report Reference CR (F) 2330

/5/ S.P.Thompson: "Neutral emission from liquid metal ion sources" Vacuum 34, 223-228 (1984)

/6/ J.Mitterauer: "Field emission electric propulsion: Emission site distribution of slit emitters"., Proc.12th Int. Conf.Discharges and Electrical Insulation in Vacuum, Shoresh, 167-171 (1986)

$17 /$ D.Laurini, H.von Rohden, C.Bartali and H.Berry: "Field emission electric propulsion (FEEP): Steady and pulsed modes of operation" 19th Int. Electric Fropulsion Conference, Colorado Springs, Paper AIAA-B7-1046 (1987)

/8/ K.L.Aitken and P.D.Prewetta "Field emission electric propulsion: Basic investigations of the ion emitting region", Final Report on ESTEC-Contract 4462/80 (1983)

19/ C.L1. Thomas, P.F.Little, C.Mahony and C.Banks: "Field emission electric propulsion: Ion optics of slit emitters and bean focussing", Final Report on ESTEC-Contract 3686/78 (1980)

/10/G.I.Taylor and A.D.MEEwan: "The stability af a horizontal fluid interface in a vertical electric field", J.Fluid Mech.,22,1 (1965) 